\title{
SUBCONJUCTIVAL INJECTION OF BEVACIZUMAB IN CORNEAL NEOVASCULARIZATION
}

\author{
Ali, Kh. ${ }^{\left.1{ }^{*}\right)}$, Abd El-badie, M. ${ }^{2}$ \& Hassan, $\mathrm{H}^{3}$ \\ ${ }^{1,2}$ Ophthalmology dept., Faculty of Medicine, AL-Azhar Univ., Assuit, Egypt \\ ${ }^{3}$ Ophthalmology dept, Faculty of Medicine, AL-Azhar Univ. Cairo, Egypt \\ *E-mail:drhaikel@yahoo.com
}

\begin{abstract}
Purpose: The aim of this work was to assess the outcome of subconjunctival bevacizumab (Avastin) injection in patients with corneal neovascularization (NV). Methods: Twenty eyes of twenty patients (13 male and 7 female) with corneal neovascularization resulted from variable ocular surface disorders were included in this prospective, non-controlled study. All eyes received a single subconjunctival injection of $2.5 \mathrm{mg}(0.1 \mathrm{ml})$ bevacizumab using $1 \mathrm{ml}$ syringe 27 Guage needle. Morphological changes in the major and minor vessels were studied by slitlamp biomicroscopy and corneal photography pre-injection and one week, 2 months and 6 months post injection. Results: Obvious recession of minor vessels of Corneal NV was noticed in most eyes at first week post-injection. The extent of corneal neovascularization of the major vessels was significantly decreased 1weeks post-injection. This decrease continued noticeably for 6 months. Conclusions: Bevacizumab can be safely and effectively used in corneal NV treatment. It can be considered in the treatment of both minor and major vessel NV resulted from long standing chronic inflammation (trachoma), long-standing corneal ischemia (following contact lens wear) and other different causes. Bevacizumab was well tolerated over the monitoring period in this research. Further controlled and long term studies are required to fully evaluate the long term effects of this recent treatment.
\end{abstract}

Keywords: Corneal neovascularization, Avastin, Subconjunctival injection

\section{Introduction}

Corneal neovascularization is a severe eye disease that can result in profound vision deterioration. The abnormal vessels can block light, cause corneal scarring and impair visual acuity, with the subsequent inflammation and edema [1]. A neovascularization of the cornea can occur secondary to chemical burns, ischemia, infection, trauma and swelling. It is a significant cause of blindness affecting up to $4.14 \%$ of patients presenting for eye care or around 1.4 million individuals annually [1]. Reports show that the extended wearing of contact lenses, infectious diseases, and a corneal transplant vascular reaction are major causes of corneal NV. Angiogenesis is known as a new blood vessel formation from the pre-existing vascular structure. Corneal neovascularization can occur by shifting 
the balance between angiogenic and antiangiogenic factors to angiogenic factors. In human and animal models, vascular endothelial growth factor was discovered to be an import antiangiogenic factor in CNV [2]. Topical corticosteroid and nonsteroidal anti-inflammatory treatment, photodynamic treatment, laser photocoagulation, fine needle diathermies, and conjunctival, limbal, and amniotic membrane transplant are the current available therapies for corneal NV. These all unfortunately have restricted clinical effectiveness and are associated with multiple undesirable effects as elevated intraocular pressure and posterior subcapsular cataracts especially with corticosteroid use. Moreover, none of them can affect the molecular mediators of angiogenesis. Targeting therapy for the anterior

\section{Patients and Methods}

\subsection{Patients}

Twenty eyes of twenty patients (13 male and 7 female) with corneal neovascularization resulting from various ocular surface disorders were be chosen from outpatient clinic of Al-AZhar Univ. hospital, Assuit, Egypt during the period between October 2014 and June 2015.

\subsubsection{Inclusion criteria}

Patients with either superficial or deep corneal NV that extend for more than $2 \mathrm{~mm}$ from the limbus were enrolled. The bright red, well defined and branching conjunctival vessels that crossed the limbus, run in superficial stromal layers and raised irregular epit-

\subsubsection{Exclusion criteria}

* Current or recent ( $\leq 3$ months) corneal or ocular surface infection.

* Ocular surgery within 3 months prior to study including keratoplasty, cataract surgery, limbal stem cell transplantation, ocular surface reconstruction, or amniotic membrane transplantation.

* Current or recent ( $\leq 3$ months) persistent corneal epithelial defects (of at least 14 days in duration measuring more than $1 \mathrm{~mm}^{2}$. segment of the eye essentially needs unique drugs that capable of passing through the intact outer epithelium [1,3]. Bevacizumab is a full-length, humanized murine monoclonal antibody that identifies all VEGF isoforms. Initially, it was approved by the U.S. Food and Drug Administration in metastatic cancer colon [4]. However, it has shown effectiveness in treatment of different neovascular ocular illness and neovascular age-related macular degeneration. In addition, topical, subconjunctival, and intraocular application of bevacizumab have showed a partial reduction of corneal neovascularization $[5,6]$. The aim of this work was to evaluate the outcome of subconjunctival bevacizumab (Avastin) injection in patients with corneal NV.

Written informed consent was obtained from all participants after approval of the study by the Institutional Ethics Committee. The off-label use of bevacizumab and its potential benefits, risks and adverse effects were discussed completely with all patients.

helium were identified as Superficial NV. While, Deep NV was known as the dark red, ill-defined, parallel and radial anterior ciliary vessels that disappeared at the limbus run in deeper stromal layers and didn't raise epithelium.

* Current or recent ( $\leq 3$ months) use of contact lens.

* Recent ( $\leq 3$ months) usage of topical steroid.

* Ocular or periocular neoplasias. In this prospective, non-controlled study, all eyes showed major and minor NV of different causes. Of the 20 eyes, corneal neovascularization was caused by healed corneal ulcers in 8eyes, healed corneal abscess in 9 eyes, and chemical burn in 3 eyes. 


\subsection{Operative procedures}

* All injections were performed in operation room.

* Topical anesthesia using 0.5\% Binoxinatehydrochloride.

* Followed by povidone iodine drops.

2.2.1. Postoperative follow-up

* Postoperative medications in the first week after operation included topical antibiotic, steroid and systemic analgesic.

* Slit-lamp bio microscopy with corneal photography was performed for evaluating the morphological changes of

\subsection{Statistical analysis}

Image analysis was performed to determine the extent of the cornea covered by $\mathrm{NV}$ in clock hours calculated as the mean \pm standard deviation (SD), over the 6-month follow-up period. Data were statistically defined in terms of mean \pm standard deviation $( \pm \mathrm{SD})$, median and range. Comparison over the study period was done using Freidman3's test with

\section{Results}

This study included 20 eyes with corneal NV, 9 of them the cause was corneal abscess, 8 of them the cause was corneal ulcer and 3 of them the cause was chemical burn, tab. (1). The age of their patients was delineated in tab. (2). According to table 2, the mean extent of neovascularization in the studied eyes decreased from $5.15 \pm 2.65$
* A single subconjunctival injection of $2.5 \mathrm{mg}(0.1 \mathrm{ml})$ bevacizumab was performed in all eyes using $1 \mathrm{ml}$ syringe 27 Guage needle.

major and minor vessels pre-injection and at one week, two and six months post injection. The extent of corneal $\mathrm{NV}$ was calculated as the number of clock-hours of limbus affected by NV (scores 1-12; score $1=1$ clock-hour, score $2=2$ clock-hours, and so on).

Wilcoxon signed rank test for paired (matched) samples as multiple post hoc 2 -group comparisons. $\mathrm{P}$ value less than 0.05 was statistically significant. Statistical tests were conducted using SPSS (Statistical Package for the Social Science; SPSS Inc., Chicago, IL, USA) computer program, version 15 for Microsoft Windows.

clock hours pre-injection to $4.45 \pm 2.41$ clock hours 1week post-injection to 3.5 \pm 2.408 clock hours 2 months postinjection to $2.9 \pm 2.34$ clock hours 6 month post-injection. Conspicuous recession of Corneal NV was observed in most eyes 1 week post-injection and this decrease continued noticeably for 6 months, tab. (3) \& fig. (1-a, b).

Table (1) Cause of Corneal NV

\begin{tabular}{|l|c|c|c|}
\multicolumn{1}{|c|}{ Cause } & Corneal abscess & Corneal ulcer & Chemical burn \\
\hline $\mathbf{N}$ & 9 & 8 & 3 \\
\hline Percentages & $45 \%$ & $40 \%$ & $15 \%$ \\
\hline
\end{tabular}

Table (2) mean and SD of study parameters

\begin{tabular}{|c|c|c|c|c|c|}
\hline & Age & $\begin{array}{c}\text { Pre- } \\
\text { injection }\end{array}$ & $\begin{array}{c}\text { 1week post } \\
\text { injection }\end{array}$ & $\frac{\text { 2-months post }}{\text { injection }}$ & $\begin{array}{c}\text { 6-months post } \\
\text { injection }\end{array}$ \\
\hline Mean & 50.8 & 5.15 & 4.45 & 3.5 & 2.9 \\
\hline $\mathbf{N}$ & 20 & 20 & 20 & 20 & 20 \\
\hline Std. Deviation & 5.035 & 2.65 & 2.41 & 2.408 & 2.34 \\
\hline Minimum & 41 & 2 & 1 & 1 & 1 \\
\hline Maximum & 60 & 12 & 11 & 10 & 10 \\
\hline Median & 50.5 & 5 & 4 & 3.00 & 2 \\
\hline
\end{tabular}


Table (3) Extent of neovascularization in clock hours before and after a single 2.5-mg subconjunctival bevacizumab injection and for 6-months of follow-up.

\begin{tabular}{|c|c|c|c|c|c|c|}
\hline $\begin{array}{c}\text { Case } \\
\text { no } \\
\end{array}$ & Age & Cause & $\begin{array}{c}\text { Pre-Avastin } \\
\text { Injection }\end{array}$ & $\begin{array}{l}1 \text { week post } \\
\text { Avastin Inj. }\end{array}$ & $\begin{array}{l}2 \text { month post } \\
\text { Avastin Inj. }\end{array}$ & \begin{tabular}{|l}
6 month post \\
Avastin Inj.
\end{tabular} \\
\hline 1 & 53 & Post ulcer & 12 & 10 & 10 & 9 \\
\hline 2 & 51 & Post abscess & 5 & 4 & 3 & 2 \\
\hline 3 & 49 & Chemical burn & 7 & 5 & 4 & 4 \\
\hline 4 & 56 & Post ulcer & 2 & 2 & 1 & 1 \\
\hline 5 & 59 & Post abscess & 5 & 4 & 3 & 3 \\
\hline 6 & 54 & Post abscess & 3 & 2 & 2 & 1 \\
\hline 7 & 55 & Post ulcer & 6 & 6 & 4 & 3 \\
\hline 8 & 60 & Chemical burn & 5 & 4 & 2 & 2 \\
\hline 9 & 48 & Post abscess & 5 & 5 & 3 & 2 \\
\hline 10 & 50 & Post ulcer & 3 & 3 & 2 & 2 \\
\hline 11 & 56 & Post ulcer & 5 & 4 & 4 & 3 \\
\hline 12 & 48 & Post ulcer & 12 & 11 & 10 & 10 \\
\hline 13 & 46 & Post ulcer & 6 & 6 & 5 & 3 \\
\hline 14 & 55 & Post abscess & 4 & 3 & 3 & 2 \\
\hline 15 & 44 & Post abscess & 3 & 3 & 2 & 2 \\
\hline 16 & 56 & Post abscess & 6 & 5 & 4 & 2 \\
\hline 17 & 48 & Post abscess & 4 & 4 & 3 & 2 \\
\hline 18 & 45 & Chemical burn & 3 & 2 & 1 & 1 \\
\hline 19 & 41 & Post ulcer & 2 & 1 & 1 & 1 \\
\hline 20 & 52 & Post abscess & 5 & 5 & 3 & 3 \\
\hline
\end{tabular}
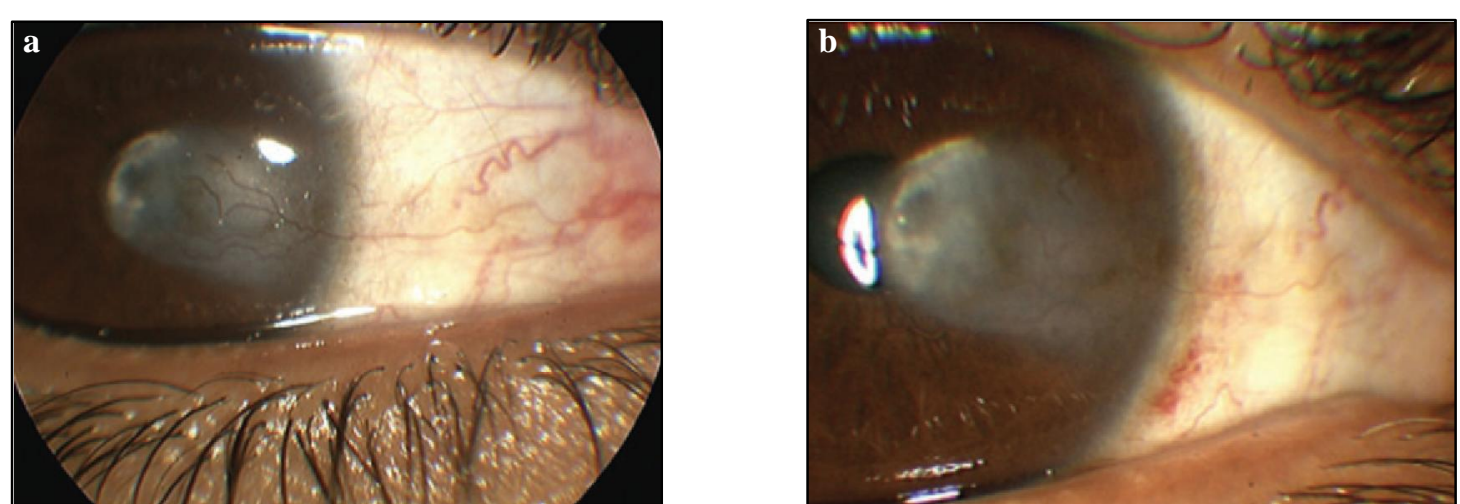

Figure (1) Shows corneal NV due to chemical burn $\underline{\text { a. }}$ before and $\underline{\mathbf{b}}$. 6 months after a single 2.5-mg (0.1-ml) bevacizumab injection.

\section{Discussion}

This prospective non-controlled study aimed to assess the outcome of subconjunctival bevacizumab injection in patients with corneal NV. The current results showed that the extent of corneal NV was significantly decreased 1 weeks postinjection and this decrease continued noticeably for 6 months. Similarly, Bahar et al. assessed subconjunctival bevacizumab in 10 patients with corneal $\mathrm{NV}$ and reported that bevacizumab decreased corneal NV by $29 \%$ with no significant ocular or systemic adverse events [7]. By the same way, Zaki \& Farid studied ten eyes with both major and minor vessel corneal NV caused by different ocular surface disorders and observed significant recession of the minor and major vessels of in all eyes at 2 weeks post-injection. In addition, the level of corneal NV continued to decrease for 3 months and then stabilized for the remainder of the 6-month follow-up period [8]. Doctor et al. reported that subconjunctival bevacizumab was able to decrease corneal $\mathrm{NV}$ in patients with ocular surface inflammatory diseases that may provide an additional strategy in improving vision 
or improving success of corneal grafts in these patients [9]. Chu et al. evaluated the effect of monthly injections of subconjunctival bevacizumab in 18 patients with NV associated with lipid keratopathy. They reported that corneal NV and lipid deposition improved significantly with bevacizumab [10]. Moreover, You et al. suggested that the efficacy of bevacizumab correlates with the injection dose [11]. When it comes to complication, no infection, inflammation or relapse was observed within the follow-up of 2-6 months. Gueudry et al. also assessed efficacy and safety of subconjunctival bevacizumab in thirteen eyes with corneal NV. They observed significant improvement in NV and visual acuity by the fourth month of follow-up without general side effects or significant change in intraocular pressure [12]. In the same point of view, Erdurmus and Totan studied the effects of subconjunctival bevacizumab injection in two eyes with corneal NV due to aqueous-deficient dry eye with filamentary keratitis in the first case, and corneal graft failure in the second case. In the first case, corneal NV was significantly regressed a week after injection while minor vessels were regressed but the major one did not in the second case without local complication or relapse during the follow-up of two to three months [13]. However, the Awadein study revealed that the immediate regretssion of the corneal vascularization and haze after single subconjunctival bevacizumab injection in 3 patients with corneal NV following keratoplasty was short-lived as the corneal vessels began to progress from the second week with permanent graft failure in all cases [14].

\section{Conclusion}

Bevacizumab can be used safely and effectively in corneal NV treatment. It can be considered in both minor and major vessel neovascularization resulted from longstanding chronic inflammation (trachoma), long-standing corneal ischaemia (related to contact lens wear) and other variable causes. In this study Bevacizumab was well tolerated during the follow up period however, further controlled and long term studies are required to completely evaluate the long term effects of this new approach.

\section{References}

1. Bahar, I., Kaiserman, I., McAllum, P., Rootman, D., Slomovic, A. Subconjunctival bevacizumab injection for corneal neovascularization. Cornea. 2008; 27: 142-147

2. De Stafeno, J., Kim, T. Topical bevacizumab therapy for corneal neovascularization. Arch Ophthalmol. 2008 ; 125: 834-836.

3. Ferrari, G., Dastjerdi, M., Okanobo, A., Cheng, S., Amparo, F., Nallasamy, N., Dana, R. Topical ranibizumab as a treatment of corneal neovascularization. Cornea. 2013; 32 (7): 992-997.

4. Saravia, M., Zapata, G., Ferraiolo, P., Racca, L., Berr, A. Anti-VEGF monoclonal antibody-induced regression of corneal neovascularization and inflammation in a rabbit model of herpetic stromal keratitis. Graefes Arch Clin Exp Ophthalmol. 2009; 247: 1409-16.

5. Bahar, I., Kaiserman, I., McAllum, P., Rootman D, Slomovic A. Subconjunctival bevacizumab injection for corneal neovascularization in recurrent pterygium. Curr Eye Res. 2008; 33: 23-28.

6. Carrasco, M. Subconjunctival bevacizumab for corneal neovascularization in herpetic stromal keratitis. Cornea. 2008; 27: 743-745.

7. Abdel Fattah, N., Amgad, M., Zayed, A., Salem, H, El Khanany, A., Hussein, H., El-Baky, N. Clinical correlates of common corneal neovascular diseases: A literature review. Int. Journal of Ophthalmology. 2015; 8 (1): 182- 193

8. Zaki, A., Farid, S. Subconjunctival bevacizumab for corneal neovascula- 
rization. Acta Ophthalmologica. 2010; 88 (8): 868-871.

9. Doctor, P., Bhat, P., Foster, C. Subconjunctival bevacizumab for corneal neovascularization. Cornea. 2008; 27 (9): 992-995.

10. Chu, H., Hu, F., Yang, C., Yeh, P., Chen, Y., Hou, Y., Chen, W. Subconjunctival injection of bevacizumab in the treatment of corneal neovascularization associated with lipid deposition. Cornea. 2011; 30 (1): 6066.

11. You, I., Kang, I., Lee, S., Yoon, K. Therapeutic effect of subconjunctival injection of bevacizumab in the treatment of corneal neovascularization. Acta Ophthalmologica 2009; 87 (6): 653-658.
12. Gueudry, J., Richez, F., TougeronBrousseau, B., Genevois, O., Muraine, M. Subconjunctival bevacizumab for corneal neovascularization. J. Francais d' Ophtalmologie. 2010; 33 (9): 630636.

13. Erdurmus, M., Totan, Y. Subconjunctival bevacizumab for corneal neov-ascularization. Graefe's Archive for Clinical and Experimental Ophtha-lmology. 2007; 245 (10): 1577-1579.

14. Awadein, A. Subconjunctival bevacizumab for vascularized rejected corneal grafts. J. of Cataract \& Refractive Surgery. 2007; 33 (11): 19911993. 